\section{Epidemiology gains an ally in bioweapons surveillance project}

Jonathan Knight, San Francisco

A system designed to track attacks involving bioweapons could also monitor the worldwide spread of infectious disease, its developers say.

Al Zelicoff, a disease surveillance expert at Sandia National Laboratory in New Mexico, presented evidence supporting the idea to a meeting of disease surveillance experts at Stanford University in Palo Alto, California, on 11 May.

The US government funded the Rapid Syndrome Validation Project (RSVP) to monitor background levels of illness against which a bioterrorist attack would stand out. "If you don't know what the noise is in a community, you sure can't find a signal above it," Zelicoff says.

At the moment, monitoring relies on clinicians to report dangerous diseases, he adds. But often they fail to do so, because most see so few cases of the maladies that they do not recognize them. As a result, outbreaks can take several weeks or more for epidemiologists to spot (see News Feature, page 232).

RSVP, which has been in use at the University of New Mexico hospital in Albuquerque since November, does not require a diagnosis. Instead, the physician enters into a computer terminal the details of any patient with one of six syndromes, such as acute respiratory distress syndrome, influenza-like illness or acute hepatitis.

The information goes over the Internet to a server in Zelicoff's office, where software identifies combinations of symptoms likely to indicate a dangerous illness. These details are then forwarded to the New Mexico state epidemiologist.

This rapid reporting already appears to have this year averted two outbreaks of hepatitis A. In both cases, the physician ordered blood tests to determine the type of hepatitis only after prompting from a state official notified by RSVP.

The physicians using RSVP also prescribed far fewer antiviral drugs for flu this year than last, probably because they got immediate information on whether or not there was any flu in their patient's community.

A major private health organization in New Mexico plans to adopt RSVP, Zelicoff says, and he is also seeking funding to try the system in other countries, where any doctor with an Internet link could potentially join it. \section{Array system promises global atmospheric monitoring}

\section{David Cyranoski, Tokyo}

A Taiwan-US collaboration is hoping that its constellation of microsatellites equipped with Global Positioning System (GPS) receivers will provide a valuable new approach to meteorology, climatology and research into 'space weather'.

Most weather forecasting currently relies on balloons that take readings such as temperature and humidity on their way up from some 900 locales worldwide. But these points are restricted to land, ruling out truly global weather models. Weather satellites give wider coverage, but they gather data by looking straight down to Earth, yielding little information about what is happening at various different altitudes.

But the Taiwan-led Constellation Observing System for Meteorology, Ionosphere and Climate (COSMIC) could change that by using an array of microsatellites and a novel technique to improve the coverage and accuracy of data collection.

The six COSMIC microsatellites, scheduled to be launched in mid-2005, will pick up radio signals from 28 existing GPS satellites as they pass through the Earth's atmosphere. The microsatellites will observe the refraction (or bending) of the atmospheric density from it, at all altitudes. From the density data, researchers will be able to deduce the pattern of pressure and temperature.

"We can also calculate atmospheric moisture near the surface, construct pressure contours, and derive wind fields and other critical quantities," says Tom Yunck of NASA's Jet Propulsion Lab (JPL), which did much of the early work on the technique.

The most important advantage is signals, and infer information about coverage. "The microsatellite constellation will measure some 4,000 points spread uniformly around the globe, with high accuracy," says Chao-Han Liu, president of Taiwan's National Central University.

Researchers on 'space weather' are also excited about the project, says Liu. In the ionosphere, at altitudes of about $80 \mathrm{~km}$, electron density can be measured in a similar fashion to the atmospheric density. This will provide valuable information for predicting magnetic storms, which can affect the operations of satellites and power grids.

The COSMIC system has the potential to significantly improve climatological measurements, says Alan Thomas, director of the Global Climate Observing System secretariat. However, he warns that it will probably take time to develop a reliable system that produces measurements for climate-change applications, and another 20 years or so after that to obtain a meaningful long-term climate data set.

The agreement to build the system, signed on 3 May, involves Taiwan's National Space Program Office (NSPO), JPL, the US University Corporation for Atmospheric Research in Boulder, Colorado, and several US universities.

Taiwan will pay US\$80 million of the estimated US $\$ 100$ million total project cost and will build the satellites with the help of Orbital Sciences Corporation of Dulles, Virginia, which made a prototype version of the satellite in 1995 for a 'proof-of-concept' experiment. Taiwan will also operate the mission.

"This is a chance to get people really interested in space science," enthuses Luo-Chang Lee, director of NSPO.

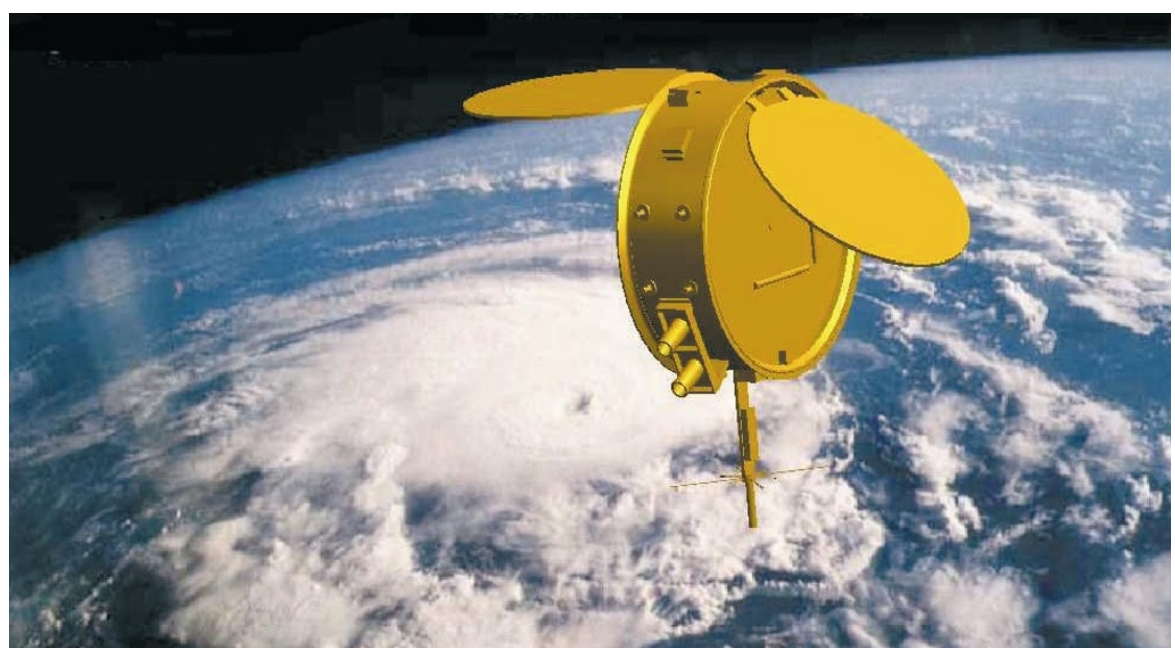

Saturation coverage: six microsatellites will improve the coverage and accuracy of climate data. 